\title{
Primary Breast Sarcoma: A rare pathology in women from the National Cancer Institute (INCan) of Mexico
}

\author{
Angélica Morales-Miranda ${ }^{*}$, L Carlos Robles-Vidal ${ }^{2}$ and Enrique Bargalló-Rocha ${ }^{2}$ \\ ${ }^{1}$ Department of Reproductive Biology, National Institute of Medical Sciences and Nutrition Salvador Zubirán, Mexico \\ ${ }^{2}$ Department of Mammary Tumors, National Cancer Institute, Mexico City 14080, Mexico
}

\begin{abstract}
Background: Primary breast sarcoma (PBS) is an extremely rare type of tumor accounting for $0.2 \%$ to $1 \%$ of all breast cancers and less than $5 \%$ of soft-tissue sarcomas. A non-epithelial breast tumor compromised of mesenchymal mammary tissue, PBS has a difficult diagnosis and no standardized treatment.

Objective: The principal aim of this study was to review the Breast Clinic data of patients diagnosed and treated for soft-tissue breast sarcoma at the National Cancer Institute in Mexico City (Instituto Nacional de Cancerología, or INCan).

Methods: A 10-year retrospective review identified only 8 patients diagnosed with PBS. All the available clinical and imaging studies (BI-RADS) were examined, as were the treatments.

Results: Independently of the tumor size, radical mastectomy was practiced on seven patients. After surgical resection, adjuvant therapy was administered to five of these patients. Half of the patients presented distant metastasis. Unfortunately, the five-year overall survival is unknown.

Conclusions: The frequency of PBS in our Institute is much less than that found in the literature. Many clinical characteristics were similar to previous reports, although the treatment was different. The appropriate diagnosis of PBS should allow for the standardization of treatment and improvement of overall survival.
\end{abstract}

\section{Introduction}

Primary breast sarcoma (PBS) is a rare type of cancer arising from the mesenchymal tissue of the breast. It accounts for $0.2 \%$ to $1 \%$ of all breast malignancies and less than $5 \%$ of all soft-tissue sarcomas [1-3]. The annual incidence, estimated at 40 new cases per 10 million women, has remained constant. The pathological classification produces controversy because the disease consists of a heterogeneous group of malignancies, as seen in soft-tissue sarcomas in other parts of the body. Accordingly, PBS includes malignant fibrous histiocytoma, fibrosarcoma, stromal sarcoma, spindle sarcoma, liposarcoma, leiomyosarcoma, osteosarcoma, chondrosarcoma, lymphomas, malignant cystosarcoma phyllodes and rhabdomyosarcoma, of which the more common subtypes are angiosarcomas, malignant fibrous histiocytoma and stromal sarcoma [4-6]. Although retrospective single institution experiences have been reported, diagnosis and treatment are based on limited data [7-10]. Unlike epithelial breast cancers, there is still no consensus on the optimal management of PBS. We herein document a retrospective review of PBS using Breast Clinic data from the National Cancer Institute in Mexico (Instituto Nacional de Cancerología, or INCan), with the aim of describing clinicopathologic features, management and prognosis. The present information is compared to reports from other institutions dedicated to the treatment of cancer.

\section{Material and methods}

Founded in 1946, the National Cancer Institute in Mexico is a tertiary care hospital that serves a population of 20 million in Mexico
City and offers consultation services to other hospitals in different regions of the country. From 2003-2008, a computer program was developed, and all records were transferred onto an electronic medical record (eMR). Currently, approximately 4,500 patients with breast cancer are treated every year in the INCan, representing $11.7 \%$ of the total number of cancer cases in this Institute. We accessed the database and retrieved all cases with a diagnosis of PBS from 2000 to 2010 (10 years), finding 8 patients out of the almost 40,000 having some type of breast malignancy. The H\&E tissue sections were examined again to confirm the histopathological diagnosis. The clinical records were retrospectively reviewed to identify clinical characteristics at the time of diagnosis regarding age, family history of breast cancer, duration of the symptoms, clinical tumor size, existence of axillary lymph nodes and/or distant metastasis, and type of surgery and adjuvant treatments (chemotherapy and/or radiotherapy).

Correspondence to: Angélica Morales-Miranda, M.D., Ph.D. Department of Reproductive Biology, National Institute of Medical Sciences and Nutrition Salvador Zubirán. Avenue Vasco de Quiroga 15 Col, Belisario Domínguez, Section XVI, Tlalpan, Mexico City 14080, Mexico

E-mail: angelica.moralesm@incmnsz.mx

Key words: primary breast sarcoma (PBS), breast imaging-reporting and data system (BI-RADS), radiotherapy, chemotherapy, prognosis, overall survival

Received: January 17, 2018; Accepted: February 06, 2018; Published: February 09, 2018 
Table 1. Clinicopathological correlation features in the present series: patient number, patient age (yrs), family history with breast carcinoma (1) or other carcinomas not involving the breast (2), tumor size, duration of symptoms, axillary lymph nodes (positive or negative), primary surgery (none (N), radical mastectomy (RM) or mastectomy (M)), adjuvant chemotherapy (none (N), ADR/Adriamycin, DTIC/Decarbazine or ISO/Isophosphamide), metastasis (LU/lung, B/bone, AD/adipose tissue, NED/no evidence of disease)

\begin{tabular}{|c|c|c|c|c|c|c|c|c|}
\hline Sample & Patient age (yrs) & $\begin{array}{c}\text { Family cancer } \\
\text { history }\end{array}$ & Tumor size (mm) & $\begin{array}{c}\text { Duration of } \\
\text { symptoms } \\
\text { (months) }\end{array}$ & $\begin{array}{l}\text { Axillary lymph } \\
\text { nodes }\end{array}$ & Primary surgery & $\begin{array}{l}\text { Adjuvant } \\
\text { Treatment }\end{array}$ & Metastasis \\
\hline 1 & 75 & 2 & $7 \times 6$ & 10 & POS & $\mathrm{N}$ & $\mathrm{N}$ & LU \\
\hline 2 & 45 & NEG & $5 \times 6$ & 7 & NEG & $\mathrm{RM}$ & ADR+DTIC & NED \\
\hline 3 & 53 & NEG & $5 \times 5$ & 3 & NEG & $\mathrm{RM}$ & $\mathrm{N}$ & NED \\
\hline 4 & 51 & NEG & $4 \times 3$ & 11 & NEG & $\mathrm{RM}$ & $\mathrm{N}$ & NED \\
\hline 5 & 63 & 1 & $3 \times 3$ & 5 & NEG & M & ISO & $\mathrm{B}$ \\
\hline 6 & 53 & 1 & $8 \times 7$ & 13 & NEG & $\mathrm{RM}$ & ADR+DTIC & $\mathrm{AD}$ \\
\hline 7 & 38 & 2 & $7 \times 6$ & 3 & POS & $\mathrm{RM}$ & ADR+ DTIC & LU \\
\hline 8 & 29 & NEG & $5 \times 6$ & 6 & NEG & $\mathrm{RM}$ & $\mathrm{ADR}+\mathrm{ISO}$ & NED \\
\hline
\end{tabular}

\section{Results}

These are summarized in Table 1 . The medical reports of the patient's evidence a median age at diagnosis of 50.8 years (range 2975 years). The clinical progression was calculated from the date of the diagnosis to the date of the first sign of change, with a median follow-up of 7.2 months (range of 1-13 months). Clinically, all patients presented a palpable mass and progressive swelling with or without pain. Palpable axillary lymphadenopathy existed only in two cases. The right breast was affected in 5 cases and the left breast in 3 . Lesion size was determined by measuring the maximum diameter, calculating the median clinical tumor size in 7 patients as $3.38 \mathrm{~cm}$ (range 3 to $8 \mathrm{~cm}$ ). In one patient the size was unknown. Standard medio-lateral oblique and cranio-caudal mammograms had been made with supplementary ultrasound images for all patients. All available images were interpreted by a team of radiologists. The findings were classified according to the American College of Radiology Breast Imaging Reporting and Data Systems (BI-RADS) lexicon [11,12]. Modified radical mastectomy and axillary lymph node dissection was the surgery of choice for one patient.

Another patient initially presented metastasis to the axillary lymph nodes and lung at the time of diagnosis and was inoperable. Six patients underwent a mastectomy and 5 of them were given adjuvant therapy. The median cycle of chemotherapy was 6 months (range 4-8). None of these patients with PBS received adjuvant radiation therapy. A distant metastasis developed in 4 patients, the most common site being the lungs and then bone and adipose tissue (consistent with current knowledge about the clinical course of soft-tissue sarcomas). Overall survival was calculated from the date of diagnosis to the date of death (for any reason) or of last contact. Four patients died of the disease and its complications (two died of lung metastasis), one of unknown cause, and three did not return for treatment (reason unknown).

\section{Discussion}

PBS is a rare disease entailing malignant tumors of the breast. Previous reports reveal that its true prevalence is difficult to determine. Between 2000 and 2010 in our institution, PBS had a prevalence of 8 in 40,000 cases of breast cancer $(0.02 \%)$, well below the rate evidenced in the literature. Given the rare nature of this malignancy, mammography and ultrasound play only a limited role in diagnostics. According to the reports with mammography, most lesions are round or oval masses with a well-circumscribed margin [13-15]. None of the masses herein observed had spiculated edges or micro-calcifications. The magnetic resonance imaging (MRI) of breasts is not a routine procedure in primary breast sarcoma but may be considered for patients with clinically advanced pathogenesis (including axillary lymph nodes positive to cancer or clinical signs or symptoms of metastasis). Previous studies demonstrate that breast sarcomas are heterogeneously hypointense on T1-weighted images and hyperintense on T2-weighted images (with intensity enhancement after the administration of contrast medium).

Histological grading is not an accurate prognostic factor. Although the first steps of tumorigenesis may be different in PBS and other sarcomas, this classic distinction is of minimal importance from a therapeutic point of view. The international consensus is that mastectomy can still be considered the gold standard. Surgical excision to clear margins is the procedure of choice, while the dissection of axillaries is not always indicated given the rareness of lymph node involvement [16-21]. Unfortunately, the role of adjuvant chemotherapy remains uncertain in the scientific literature $[22,23]$, while the role and the timing of radiation and chemotherapy (pre-surgical vs. postsurgical) has varied [24-26]. Lung, bone and liver are the most common sites for metastasis. Hematic dissemination is the predominant via, although some reports suggest that lymphatic migration may also occur [27-30]. Recent single-institution case series demonstrate that tumor size and margin status are the best prognostic factors for PBS. A tumor size $>5 \mathrm{~cm}$ is the only significant prognostic indicator of poor survival. The 5-year overall survival rate of PBS is similar to that found for non-breast sarcomas, with a very poor prognosis and no specific treatment guidelines.

\section{Conclusions}

PBS requires a multidisciplinary team involving an oncologist, breast surgeon, radiologist, pathologist and chemotherapy oncologist for determining the treatment that offers the best probability of patient survival. According to previous reports, it is unclear which treatment can optimize long-term survival.

\section{Acknowledgments}

The authors are grateful to their assistants for acquisition of the data used in this review. The corresponding author acknowledges all scientists for their previous reports and review about PBS.

\section{Competing interests}

The authors declare that they have no conflicts of interest.

\section{References}

1. Lum YW, Jacobs L (2008) Primary Breast Sarcoma. Surg Clin North Am 88: 559570

2. Ciatto S, Bonardi R, Cataliotti L, Cardona G (1992) Sarcomas of the breast: a multicenter series of 70 cases. Neoplasma 39: 375-379. [Crossref] 
3. Kennedy T, Biggart JD (1967) Sarcoma of the breast. Br J Cancer 21: 635-644. [Crossref]

4. Yang WT, Hennessy BT, Dryden MJ, Valero V, Hunt KK, et al. (2007) Mammary angiosarcomas: imaging findings in 24 patients. Radiology 242: 725-734. [Crossref]

5. Horii R, Fukuuchi A, Nishi T, Takanashi R (2000) A case of malignant fibrous histiocytoma after breast conserving therapy for breast cancer. Breast Cancer 7: 75-77. [Crossref]

6. Berg JW, Decrosse JJ, Fracchia AA, Farrow J (1962) Stromal sarcomas of the breast. A unified approach to connective tissue sarcomas other than cystosarcoma phyllodes. Cancer 15: 418-424. [Crossref]

7. Pollard SG, Marks PV, Temple LN, Thompson HH (1990) Breast sarcoma. A clinicopathologic review of 25 cases. Cancer 66: 941-944. [Crossref]

8. Adem C, Reynolds C, Ingle JN, Nascimento AG (2004) Primary breast sarcoma: clinicopathologic series from the Mayo Clinic and review of the literature. Br J Cancer 91: 237-241. [Crossref]

9. Callery CD, Rosen PP, Kinne DW (1985) Sarcoma of the breast. A study of 32 patients with reappraisal of classification and therapy. Ann Surg 201: 527-532. [Crossref]

10. Terrier P, Terrier-Lacombe MJ, Mouriesse H, Friedman S, Spielmann M, et al. (1989) Primary breast sarcoma: a review of 33 cases with immunohistochemistry and prognostic factors. Breast Cancer Res Treat 13: 39-48. [Crossref]

11. Kim EK, Ko KH, Oh KK, Kwak JY, You JK, et al. (2008) Clinical application of the BI-RADS final assessment to breast sonography in conjunction with mammography. AJR Am J Roentgenol 190: 1209-1215. [Crossref]

12. Lehman C, Holt S, Peacock S, White E, Urban N (2002) Use of the American College of Radiology BI-RADS guidelines by community radiologists: concordance of assessments and recommendations assigned to screening mammograms. AJR Am J Roentgenol 179: 15-20. [Crossref]

13. Szabó BK, Aspelin P, Wiberg MK, Boné B (2003) Dynamic MR imaging of the breast Analysis of kinetic and morphologic diagnostic criteria. Acta Radiol 44: 379-386. [Crossref]

14. Surov A, Holzhausen HJ, Ruschke K, Spielmann RP (2011) Primary breast sarcoma: prevalence, clinical signs, and radiological features. Acta Radiol 52: 597-601. [Crossref]

15. Pasta V, Monti M, Cialini M, Vergine M, Urciuoli P, et al. (2015) Primitive sarcoma of the breast: new insight on the proper surgical management. J Exp Clin Cancer Res 34: 72. [Crossref]

16. Morrow M, Jagsi R, Alderman AK, Griggs JJ, Hawley ST, et al. (2009) Surgeon recommendations and receipt of mastectomy for treatment of breast cancer. JAMA 302: 1551-1556. [Crossref]
17. Opatt D, Morrow M, Hawley S, Schwartz K, Janz NK, et al. (2007) Conflicts in decision-making for breast cancer surgery. Ann Surg Oncol 14: 2463-2469. [Crossref]

18. Fields RC, Aft RL, Gillanders WE, Eberlein TJ, Margenthaler JA (2008) Treatment and outcomes of patients with primary breast sarcoma. Am J Surg 196: 559-561. [Crossref]

19. Gutman H, Pollock RE, Ross MI, Benjamin RS, Johnston DA, et al. (1994) Sarcoma of the breast: implications for extent of therapy. The M. D. Anderson experience. Surgery 116: 505-509. [Crossref]

20. Khatcheressian JL, Wolff AC, Smith TJ, Grunfeld E, Muss HB, et al. (2006) American Society of Clinical Oncology 2006 update of the breast cancer follow-up and management guidelines in the adjuvant setting. J Clin Oncol 24: 5091-5097. [Crossref]

21. Bramwell VHC, Anderson D, Charette ML (2000) Doxorubicin-based chemotherapy for the palliative treatment of adult patients with locally advanced or metastatic softtissue sarcoma: a meta-analysis and clinical practice guideline. Sarcoma 4: 103-112.

22. Wesolowski R, Budd GT (2010) Use of chemotherapy for patients with bone and softtissue sarcomas. Cleve Clin J Med 77: 23-26. [Crossref]

23. Barrow BJ, Janjan NA, Gutman H, Benjamin RS, Allen P, et al. (1999) Role of radiotherapy in sarcoma of the breast-a retrospective review of the M.D. Anderson experience. Radiother Oncol 52: 173-178. [Crossref]

24. Blanchard DK, Reynolds C, Grant CS, Farley DR, Donohue JH (2002) Radiationinduced breast sarcoma. Am J Surg 184: 356-358. [Crossref]

25. Sheppard DG, Libshitz HI (2001) Post-radiation sarcomas: a review of the clinical and imaging features in 63 cases. Clin Radiol 56: 22-29. [Crossref]

26. Mazeron JJ, Suit HD (1987) Lymph nodes as sites of metastases from sarcomas of soft tissue. Cancer 60: 1800-1808. [Crossref]

27. McGowan TS, Cummings BJ, O’Sullivan B, Catton CN, Miller N, et al. (2000) An analysis of 78 breast sarcoma patients without distant metastases at presentation. Int $J$ Radiat Oncol Biol Phys 46: 383-390. [Crossref]

28. Behranwala KA, A’Hern R, Omar AM, Thomas JM (2004) Prognosis of lymph node metastasis in soft tissue sarcoma. Ann Surg Oncol 11: 714-719. [Crossref]

29. Billingsley KG, Burt ME, Jara E, Ginsberg RJ, Woodruff JM, et al. (1999) Pulmonary metastases from soft tissue sarcoma: analysis of patterns of diseases and postmetastasis survival. Ann Surg 229: 602-610. [Crossref]

30. Zelek L, Llombart-Cussac A, Terrier P, Pivot X, Guinebretiere JM, et al. (2003) Prognostic factors in primary breast sarcomas: a series of patients with long-term follow-up. J Clin Oncol 21: 2583-2588. [Crossref]

Copyright: (C)2018 Morales-Miranda A. This is an open-access article distributed under the terms of the Creative Commons Attribution License, which permits unrestricted use, distribution, and reproduction in any medium, provided the original author and source are credited. 